\title{
Article \\ Commercial Gold Complexes Supported on Functionalised Carbon Materials as Efficient Catalysts for the Direct Oxidation of Ethane to Acetic Acid
}

\author{
Ana P. C. Ribeiro ${ }^{1}\left(\mathbb{D}\right.$, Inês A. S. Matias ${ }^{1}\left(\mathbb{D}\right.$, Sónia A. C. Carabineiro ${ }^{1,2,3, * \mathbb{C}}$ and Luísa M. D. R. S. Martins ${ }^{1, * \mathbb{C}}$ \\ 1 Centro de Química Estrutural, Institute of Molecular Sciences, Departamento de Engenharia Química, \\ Instituto Superior Técnico, Universidade de Lisboa, Av. Rovisco Pais, 1049-001 Lisboa, Portugal; \\ apribeiro@tecnico.ulisboa.pt (A.P.C.R.); ines.matias@tecnico.ulisboa.pt (I.A.S.M.) \\ 2 Laboratory of Catalysis and Materials (LCM), Associate Laboratory LSRE-LCM, Faculty of Engineering, \\ University of Porto, 4200-465 Porto, Portugal \\ 3 LAQV-REQUIMTE, Department of Chemistry, NOVA School of Science and Technology, \\ Universidade NOVA de Lisboa, 2829-516 Caparica, Portugal \\ * Correspondence: sonia.carabineiro@fct.unl.pt (S.A.C.C.); luisammartins@tecnico.ulisboa.pt (L.M.D.R.S.M.)
}

check for updates

Citation: Ribeiro, A.P.C.; Matias,

I.A.S.; Carabineiro, S.A.C.; Martins, L.M.D.R.S. Commercial Gold

Complexes Supported on

Functionalised Carbon Materials as

Efficient Catalysts for the Direct

Oxidation of Ethane to Acetic Acid.

Catalysts 2022, 12, 165. https://

doi.org/10.3390/catal12020165

Academic Editor: Valeria La Parola

Received: 7 January 2022

Accepted: 24 January 2022

Published: 28 January 2022

Publisher's Note: MDPI stays neutral with regard to jurisdictional claims in published maps and institutional affiliations.

Copyright: (C) 2022 by the authors. Licensee MDPI, Basel, Switzerland. This article is an open access article distributed under the terms and conditions of the Creative Commons Attribution (CC BY) license (https:/ / creativecommons.org/licenses/by/ $4.0 /)$.

\begin{abstract}
The single-pot efficient oxidation of ethane to acetic acid catalysed by $\mathrm{Au}(\mathrm{I})$ or $\mathrm{Au}(\mathrm{III})$ compounds, chlorotriphenylphosphinegold(I) (1), chlorotrimethylphosphinegold(I) (2), 1,3-bis(2,6diisopropylphenyl)imidazol-2-ylidenegold(I) chloride (3), dichloro(2-pyridinecarboxylato)gold(III) (4), homogenous and supported on different carbon materials: activated carbon (AC), multi-walled carbon nanotubes (CNT) and carbon xerogel (CX), oxidised with nitric acid followed by treatment with $\mathrm{NaOH}(-\mathrm{ox}-\mathrm{Na})$, is reported. The reactions were performed in water/acetonitrile. The materials were selective for the production of acetic acid, with no trace of by-products being detected. The best homogenous catalysts were complexes 2 and $\mathbf{3}$ which showed the highest ethane conversion and an acetic acid yield of ca. $21 \%$, followed by 4 and 1 . The heterogenised materials showed much better activity than the homogenous counterparts, with acetic acid yields up to $41.4 \%$ for $4 @ \mathrm{CNT}-\mathrm{ox}-\mathrm{Na}$, and remarkable selectivity (with acetic acid being the only product detected). The heterogenised catalysts with the best results were reused up to five cycles, with no significant loss of activity, and maintaining high selectivity for acetic acid. 4@CNT-ox-Na showed not only the best catalytic activity but also the best stability during the recycling runs.
\end{abstract}

Keywords: ethane oxidation; acetic acid; gold; carbon; heterogeneous catalysis

\section{Introduction}

Direct ethane oxidation is difficult to achieve due to the low reactivity of the C-H bond. The kinetic labile products also increase the difficulty of this potentially rewarding reaction [1]. Economically speaking, this reaction is important, as several bulk chemicals rely on the ethane oxidation products. Among them, acetic acid is the most sought product [2]. It is commercially produced mainly from methanol carbonylation [3], which gives rise to several environmental problems. Methanol carbonylation is responsible for $65 \%$ of the world capacity, the remaining $35 \%$ being distributed between oxidation of $n$-butane, acetaldehyde, naphtha and fermentation of hydrocarbons [4].

A new commercial procedure to obtain acetic acid that can replace the carbonylation of methanol is needed. It is important to avoid the use of corrosive chemicals and consequent waste disposal. The economy related to general commodities makes the possibility of new procedures to produce acetic acid a key challenge for catalysis research.

The development of an environmental awareness for catalysis research led to emerging legislation for the impact of chemicals, such as $\mathrm{CO}_{2}$ and methane emission. In addition, the decrease in oil reserves provided the opportunity for exploring alternative feedstocks to produce several commodities. Despite the gas synthesis route of acetic acid being 
currently an economically appealing process for the production of acetic acid in large-scale (Cativa $^{\mathrm{TM}}$ process) [3], many energy-demanding intermediate steps augment the total costs of production. Thus, simpler and more economical procedures to produce acetic acid are needed.

The most reported catalysts for the oxidation of ethane are mixtures of calcinated oxides with selectivities up to $96 \%$; however, neither the conversion nor the yield are high. Some reviews can be found on the subject [5-7]. The pioneer work of Thorsteinson et al. [8] reports on the selective oxidation of ethane to produce acetic acid on oxide-based catalysts containing Mo, V, and other elements ( $\mathrm{Nb}$, Sb, Ti, Ta, Sn, As, W, Fe). These authors stated that ethylene is produced as a principal product, and acetic acid was formed only at higher pressures as a result of subsequent oxidation of ethylene. Several researchers used Mo-V oxides [9,10], sometimes doped with Al [11,12], Nb [13-19], Pd [16,19] or Nb and $\mathrm{Pd}[20,21]$. Mo-V with redox elements $(\mathrm{Pd}, \mathrm{Ni}, \mathrm{Ti})$ and acid elements $(\mathrm{K}, \mathrm{Cs}, \mathrm{Te})$ were also reported, with acetic acid yield maximised for a $\mathrm{Mo}_{8} \mathrm{~V}_{2} \mathrm{Nb}_{1} \mathrm{Ti}_{0.005} \mathrm{Te}_{1}$ catalyst [22] Mo-V-M-O ( $\mathrm{M}=\mathrm{Al}, \mathrm{Fe}, \mathrm{Cr}$ or $\mathrm{Ti}$ ) complex metal oxide catalysts were also tested [23]. Mo-V materials, frequently doped with other elements, supported on silica [24] and titania [25-30] were also described. Molybdo(vanado)phosphoric heteropoly acids with Keggin structure on oxide supports $\left(\mathrm{SiO}_{2}, \mathrm{Al}_{2} \mathrm{O}_{3}, \mathrm{TiO}_{2}\right)$ are found in the literature [31]. V-P-O oxides were tested [13,32,33], sometimes doped with Mo [32] or supported on titania [25,33]. In addition, titania has been used as a support for $\mathrm{VO}_{x}$ catalysts [33,34], along with zirconia [34]. It is not easy to determine which is the actual active and selective phase, as recently stated by Bordes-Richard [7].

Zeolites, such as H-ZSM-5 [35], iron and copper containing ZSM-5 [36,37], Fe/ZSM-5 [37,38], Rh/HZSM-5 [39], platinum and zinc containing LTA zeolite catalysts [40] were used towards the oxidation of ethane, but selectivities do not go beyond $80 \%$, and yields and conversions are still low.

Other catalysts include the iridium clusters and atomically dispersed iridium catalysts on nanodiamond support [41], pyrazole and tris(pyrazolyl)methane rhenium complexes (with a remarkable $40 \%$ acetic acid yield) [42,43], or silica, graphite or nafion supported mu-nitrido diiron phthalocyanines [44].

Recently, a highly selective oxidation of ethane to acetic acid was achieved by us [45], using a $\mathrm{Fe}_{3} \mathrm{O}_{4} / \mathrm{TiO}_{2} /\left[\mathrm{FeCl}_{2}\left\{\kappa^{3}-\mathrm{HC}(\mathrm{pz})_{3}\right\}\right]$ composite, where the C-scorpionate iron(II) catalyst was immobilised at the magnetic core-shell $\left(\mathrm{Fe}_{3} \mathrm{O}_{4} / \mathrm{TiO}_{2}\right)$ support.

Gold catalysts have been widely used in many reactions as shown by several reviews [46-49]. However, the only references found in the literature for the use of gold in ethane oxidation are from the work of Wang et al., dealing with non-supported Au-Pd nanoparticles in water, but the main product obtained was ethyl hydroperoxide [50] and our own work dealing with homogeneous N-heterocyclic carbene and oxo-carbene $\mathrm{Au}(\mathrm{I})$ compounds [51]. Therefore, to the best of our knowledge, the present work reports the first use of commercial gold complexes supported on carbon nanomaterials in the oxidation of ethane to produce acetic acid. These complexes had already been used in the oxidation of alcohols and alkanes, in a previous work of ours, with good results [52]. Herein, the one-step oxidation of ethane to acetic acid using a supported catalyst and a mixture of solvents (water and acetonitrile) is reported as a new procedure for ethane oxidation. The present method uses an environmentally sustainable approach, with milder conditions and some commercial catalysts, with good activity and a selectivity of $100 \%$ to acetic acid. This is an important step that will contribute considerably to the efficient use of feedstocks.

\section{Results and Discussion}

\subsection{Carbon Supports Characterisation}

The carbon-based materials used were activated carbon (AC), multi-walled carbon nanotubes (CNT) and carbon xerogel (CX), oxidised with $\mathrm{HNO}_{3}$ and afterwards treated with $\mathrm{NaOH}$ (-ox-Na). Table 1 and Figure 1 show the characterisation results of the original supports and after the treatment. 
$\mathrm{AC}$ has a high surface area and a great deal of micropores, as expected [52-58]. However, CX is mainly mesoporous, also as expected [53,57-59]. Carbon nanotubes are cylindrical, and the porosity comes from the free spaces of the bundles, which results in a lower surface area [53,57-59]. The ox-Na treatment causes the collapse of the pores of AC and $\mathrm{CX}$, decreasing the surface area and pore volume. On CX, the average mesopore width is increased. For CNT, an increase in area is found, possibly due to the opening of some CNT tips with the harsh oxidative treatment.

Figure 1 shows the temperature programmed desorption (TPD) profiles before and after the treatment. It is not surprising that the -ox- $\mathrm{Na}$ treatment largely increased the $\mathrm{CO}$ and $\mathrm{CO}_{2}$ quantities desorbed (Table 1). The carboxylic acids (that decompose around 200-350 ${ }^{\circ} \mathrm{C}$ as $\mathrm{CO}_{2}[53-56,60]$ largely increase in treated samples (Figure $\left.1 \mathrm{~b}, \mathrm{~d}, \mathrm{f}\right)$. Concerning the $\mathrm{CO}$ profiles (Figure $1 \mathrm{a}, \mathrm{c}, \mathrm{e}$ ), desorption starts around $350{ }^{\circ} \mathrm{C}$ for the $\mathrm{AC}$-ox-Na and CX-ox-Na samples, but only at around $500{ }^{\circ} \mathrm{C}$ for the CNT-ox-Na material. This is caused by the decomposition of stable carboxylates and phenolates [59] that desorb as $\mathrm{CO}$ at that range of temperatures [53-56,60].
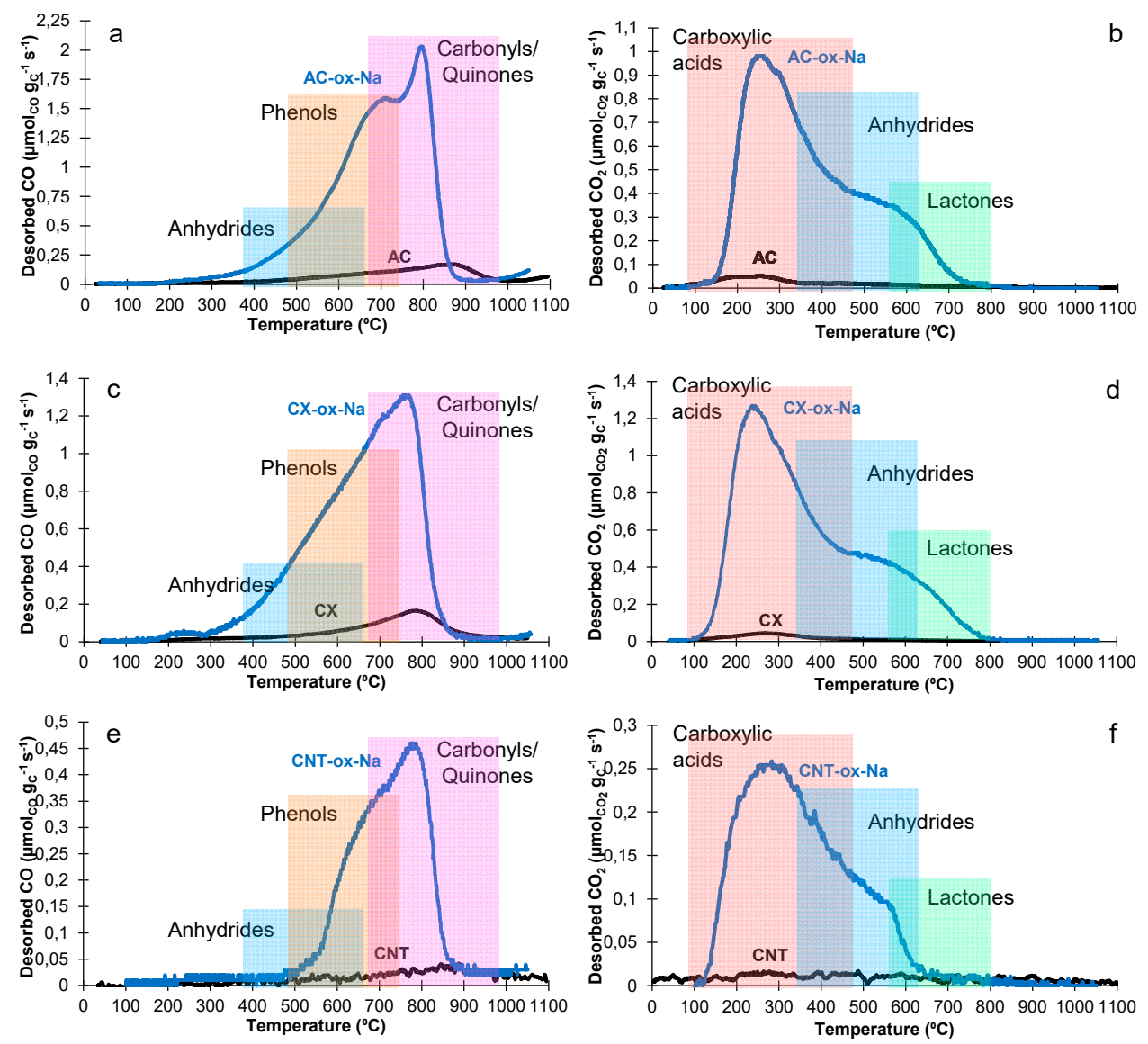

Figure 1. TPD results for $\mathrm{AC}(\mathbf{a}, \mathbf{b}), \mathrm{CX}(\mathbf{c}-\mathbf{e})$ and $C N T(\mathbf{e}, \mathbf{f})$. Desorption as $\mathrm{CO}(\mathbf{a}, \mathbf{c}, \mathbf{e})$ and $\mathrm{CO}_{2}(\mathbf{b}, \mathbf{d}, \mathbf{f})$. The colour bars show the expected temperature ranges for the desorption of the diverse groups (adapted from [52,61]). 
Table 1. Carbon samples characterisation: surface area $\left(\mathrm{S}_{\mathrm{BET}}\right)$, average mesopore width $(\mathrm{L})$, total pore volume $\left(\mathrm{V}_{\mathrm{p}}\right)$, micropore volume $\left(\mathrm{V}_{\text {micro }}\right)$, determined by adsorption of $\mathrm{N}_{2}$ at $-196{ }^{\circ} \mathrm{C}$, and quantities of $\mathrm{CO}$ and $\mathrm{CO}_{2}$ desorbed, obtained by TPD. Adapted from $[52,61]$.

\begin{tabular}{ccccccc}
\hline Sample & $\mathbf{S}_{\text {BET }}\left(\mathbf{m}^{2} / \mathbf{g}\right)$ & $\mathbf{V}_{\mathbf{p}}\left(\mathbf{c m}^{\mathbf{3}} / \mathbf{g}\right)$ & $\mathbf{L}(\mathbf{n m})$ & $\mathbf{V}_{\text {mic }}\left(\mathbf{c m}^{3} / \mathbf{g}\right)$ & $\mathbf{C O}(\mu \mathbf{m o l} / \mathbf{g})$ & $\mathbf{C O}_{\mathbf{2}}(\mu \mathbf{m o l} / \mathbf{g})$ \\
\hline AC & 974 & 0.67 & - & 0.34 & 643 & 179 \\
AC-ox-Na & 610 & 0.35 & - & 0.251 & 5012 & 2883 \\
CNT & 257 & 2.89 & & $\sim 0$ & 142 & 89 \\
CNT-ox-Na & 350 & 1.45 & - & $\sim 0$ & 1079 & 838 \\
CX & 604 & 0.91 & 13.7 & $\sim 0$ & 492 & 135 \\
CX-ox-Na & 560 & 0.75 & 17.6 & 0.036 & 3720 & 3793 \\
\hline
\end{tabular}

\subsection{Heterogenisation Efficiency}

The readily available $\mathrm{Au}(\mathrm{I})$ and $\mathrm{Au}(\mathrm{III})$ commercial complexes chlorotriphenylphosphinegold(I) (1), chlorotrimethylphosphinegold(I) (2), 1,3-bis(2,6-diisopropylphenyl)imidazol-2ylidenegold(I) chloride (3) and dichloro(2-pyridinecarboxylato)gold(III) (4) (Figure 2) were used as catalysts towards the conversion of ethane into acetic acid. These materials had already been used in the oxidation of alcohols and alkanes in a previous work of ours [52].

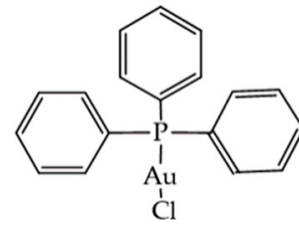

(1)<smiles>C[PH](C)(C)[Al]Cl</smiles>

(2)

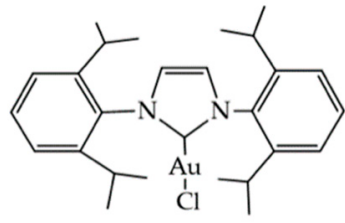

(3)<smiles></smiles>

(4)

Figure 2. Structures of commercial chlorotriphenylphosphinegold(I) (1), chlorotrimethylphosphinegold(I) (2), 1,3-bis(2,6-diisopropylphenyl)imidazol-2-ylidenegold(I) chloride (3) and dichloro(2pyridinecarboxylato)gold(III) (4).

The Au compounds were anchored on the different functionalised carbon materials. The intended value was $2 \%$ Au loading, but several amounts were obtained on the different carbon materials (Table 2). As shown above, the treatment affects the porous structure and surface properties of the carbon supports. However, all of them were able to anchor the complexes, but with different efficiencies (Table 2). Functionalisation of the supports leads to an increase the amount of surface groups that can "anchor" the compounds [59,61-63]. Complex 4 heterogenises similarly on all supports. The other complexes, in general, anchor better on AC-ox-Na. Nevertheless, the values obtained for complexes 2-4 are similar in all carbon materials, showing that the phenolates and carboxylate groups present in these supports (known to be more stable and help anchorage of complexes on the carbon materials [59,61-63]) have a larger effect on heterogenisation than the nature of the support itself. Complex 1 has a slightly worse behaviour on CX-ox-Na, but similar results are found for the other complexes. Complex 3 has the lowest heterogenisation amounts. It is possible that the steric effect caused by its large diisopropylphenyl moieties prevents a larger heterogenisation degree.

Table 2. Gold loading ( $\mathrm{mmol} / \mathrm{g}$ ) of the complexes 1-4 heterogenised on carbon materials (data from [52]).

\begin{tabular}{cccc}
\hline & @AC-ox-Na & @CX-ox-Na & @CNT-ox-Na \\
\hline $\mathbf{1}$ & 0.20 & 0.01 & 0.17 \\
\hline $\mathbf{2}$ & 0.05 & 0.06 & 0.04 \\
\hline $\mathbf{3}$ & 0.03 & 0.02 & 0.03 \\
\hline $\mathbf{4}$ & 0.10 & 0.10 & 0.10 \\
\hline
\end{tabular}




\subsection{Oxidation of Ethane to Acetic Acid}

The commercial $\mathrm{Au}(\mathrm{I})$ and $\mathrm{Au}(\mathrm{III})$ complexes 1-4 (Figure 2) were used as catalysts for the oxidation of ethane to acetic acid. The reaction was carried out using potassium peroxodisulfate as oxidant, in several reaction media/conditions (Table 3). The optimised conditions were found to be the use of aqueous acetonitrile, at $80{ }^{\circ} \mathrm{C}$, during $20 \mathrm{~h}$. All the Au compounds exhibited significant selectivity (acetic acid being the only product detected) and good activity (Figure 3). Blank runs in the presence of ethane and potassium peroxodisulfate (metal-free, determined by ICP) were carried out under the found optimised conditions, which allowed for confirmation that acetic acid was only detected when a gold catalyst was present in the reaction mixture.

Table 3. Results for the direct oxidation of ethane to acetic acid catalysed by compounds 1-4 in homogenous conditions ${ }^{a}$.

\begin{tabular}{|c|c|c|c|c|c|c|}
\hline Entry & Catalyst & Temperature $\left({ }^{\circ} \mathrm{C}\right)$ & Solvent & Yield $^{b}(\%)$ & TON $^{c}$ & TOF $^{d}$ \\
\hline 1 & \multirow{4}{*}{1} & 80 & TFA & 4.9 & 54 & 3 \\
\hline 2 & & 80 & $\mathrm{ACN} / \mathrm{H}_{2} \mathrm{O}$ & 12.7 & 141 & 7 \\
\hline 3 & & 50 & TFA & 0 & 0 & 0 \\
\hline 4 & & 50 & $\mathrm{ACN} / \mathrm{H}_{2} \mathrm{O}$ & 0.1 & 0 & 0 \\
\hline 5 & \multirow{4}{*}{2} & 80 & TFA & 4.4 & 49 & 3 \\
\hline 6 & & 80 & $\mathrm{ACN} / \mathrm{H}_{2} \mathrm{O}$ & 20.4 & 226 & 11 \\
\hline 7 & & 50 & TFA & 3.2 & 35 & 2 \\
\hline 8 & & 50 & $\mathrm{ACN} / \mathrm{H}_{2} \mathrm{O}$ & 5.3 & 59 & 3 \\
\hline 9 & \multirow{4}{*}{3} & 80 & TFA & 14.2 & 157 & 8 \\
\hline 10 & & 80 & $\mathrm{ACN} / \mathrm{H}_{2} \mathrm{O}$ & 20.9 & 231 & 12 \\
\hline 11 & & 50 & TFA & 0 & 0 & 0 \\
\hline 12 & & 50 & $\mathrm{ACN} / \mathrm{H}_{2} \mathrm{O}$ & 0.2 & 0 & 0 \\
\hline 13 & \multirow{4}{*}{4} & 80 & TFA & 8.9 & 98 & 5 \\
\hline 14 & & 80 & $\mathrm{ACN} / \mathrm{H}_{2} \mathrm{O}$ & 15.7 & 174 & 9 \\
\hline 15 & & 50 & TFA & 3.1 & 34 & 2 \\
\hline 16 & & 50 & $\mathrm{ACN} / \mathrm{H}_{2} \mathrm{O}$ & 5.2 & 58 & 3 \\
\hline
\end{tabular}

${ }^{a}$ Reaction conditions (unless otherwise stated): $p \mathrm{C}_{2} \mathrm{H}_{6} 3$ atm, $1.5 \mathrm{mmol}$ of catalyst (1-4), $\mathrm{K}_{2} \mathrm{~S}_{2} \mathrm{O}_{8}(4.33 \mathrm{mmol})$ $20 \mathrm{~h}$. Reactions were performed in $5.5 \mathrm{~mL}$ of TFA or $6 \mathrm{~mL}$ of water/acetonitrile mixture. ${ }^{b}$ Yield $(\%)=$ mol of acetic acid $/ 100 \mathrm{~mol}$ of ethane. ${ }^{c} \mathrm{TON}=\mathrm{mol}$ of acetic acid $/ \mathrm{mol}$ of catalyst $(\mathbf{1}-4) .{ }^{d} \mathrm{TOF}=(\mathrm{mol}$ of acetic acid $/ \mathrm{mol}$ of catalyst (1-4))/time.

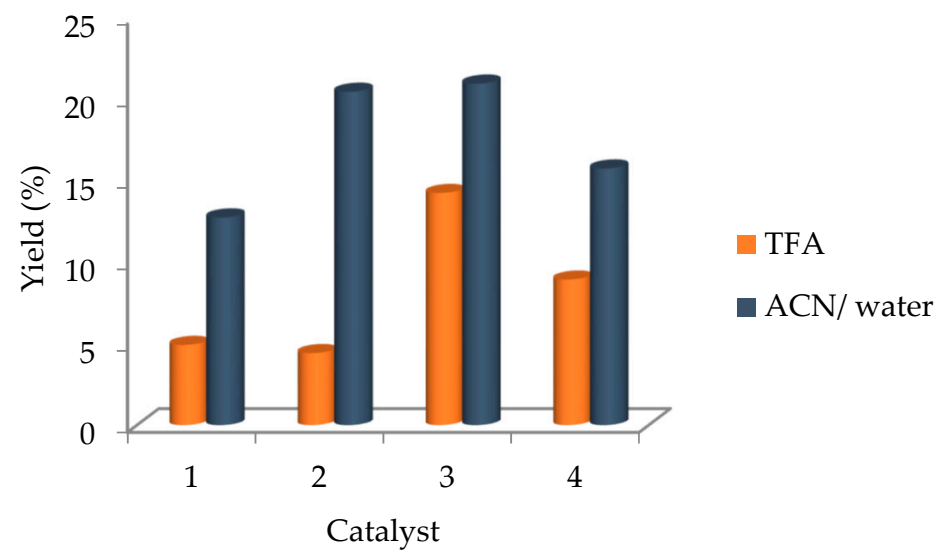

Figure 3. Acetic acid yields obtained by oxidation of ethane catalysed by the commercial gold complexes 1-4, using $\mathrm{K}_{2} \mathrm{~S}_{2} \mathrm{O}_{8}$, under optimised conditions.

The gold(I) catalysts chlorotrimethylphosphinegold(I) (2) and 1,3-bis(2,6-diisopropylphenyl) imidazol-2-ylidenegold(I) chloride (3) afforded the highest ethane conversion with an acetic acid yield of ca. 21\% (Figure 3 and Table 3), followed by dichloro(2-pyridinecarboxylato) 
gold(III) (4) and chlorotriphenylphosphinegold(I) (1). The electronic withdrawing ligand $\mathrm{PPh}_{3}$ associated to its steric hindrance, appears to contribute for the achievement of a lower yield of acetic acid relative to catalysts $2-4$, although maintaining the oxidative selectivity. The herein obtained yields (up to $21 \%$ ) are lower than the recently reported (33-39.8\%) for homogeneous $\mathrm{N}$-heterocyclic carbene and oxo-carbene gold(I) catalysts [51]. However, we should keep in mind the advantageous availability of the commercial Au compounds relative to harder-to-prepare and less stable carbene complexes.

The literature common solvent for ethane oxidation, trifluoroacetic acid (TFA) [64,65], was also tested with the gold complexes 1-4. As presented in Figure 3, the performance of all catalysts decreases considerably in TFA when compared with the exhibited in the greener aqueous mixture: a maximum of $14.2 \%$ yield of acetic acid is attained for complex 3, whereas for complexes 1, 2 and 4, an even more marked yield reduction (Table 3) is observed.

Despite the above promising results in the water/acetonitrile mixture, the major drawback presented by the homogeneous catalysts 1-4 is their lack of recyclability. Therefore, the gold complexes 1-4 were supported on functionalised carbon materials (Section 2.2) and applied as heterogeneous catalysts for the oxidation of ethane to produce acetic acid (Scheme 1). The selected carbon supports were oxidised with nitric acid and subsequently treated with sodium hydroxide (-ox-Na).

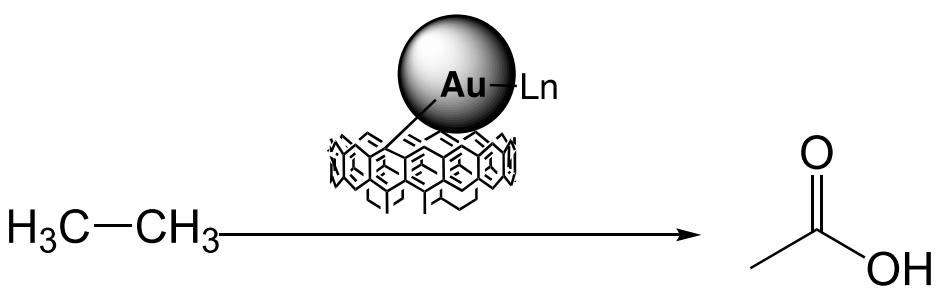

Scheme 1. Acetic acid formation by selective oxidation of ethane catalysed by the commercial gold complexes 1-4 immobilised on carbon materials, using $\mathrm{K}_{2} \mathrm{~S}_{2} \mathrm{O}_{8}$.

The reactions were performed using potassium peroxodisulfate as an oxidant in several reaction media/conditions (selected results presented in Table 4) to reach the optimised heterogeneous catalytic systems. As found in homogeneous conditions (see above), aqueous acetonitrile, at $80^{\circ} \mathrm{C}$, for $20 \mathrm{~h}$, provided the best results (Table 4). Blank runs in the presence of ethane, potassium peroxodisulfate and each carbon material were carried out under the found optimised conditions, which allowed for confirmation that acetic acid was only detected when a gold catalyst was present in the reaction mixture.

All hybrid catalysts obtained by immobilisation of the gold complexes on the carbon materials exhibited an amazing selectivity (only acetic acid was detected) and a clearly improved catalytic performance relative to the homogeneous analogues (compare Tables 3 and 4). Indeed, under optimised conditions, the hybrid catalysts allowed for attainment of up to $41.4 \%$ yield of acetic acid (entry 32 of Table 3, for catalyst $4 @ \mathrm{CNT}-\mathrm{ox}-\mathrm{Na}$ ), whereas a maximum of $20.9 \%$ yield was reached under homogeneous conditions (entry 10 of Table 3, for catalyst 3). Moreover, an increase of 10 times on the catalyst amount (from 1.5 to $15 \mu \mathrm{mol} \mathrm{Au}$ ) did not impart a significant changing of the acetic acid formed (compare e.g., entries 12 and 14, Table 4). It is possible that a larger amount of catalyst can lead to mixing problems and possible agglomeration of material (which decreases the number active catalyst sites). Thus, the lower loading $(1.5 \mu \mathrm{mol} \mathrm{Au})$ was chosen as the optimum amount. It is worth highlighting the low catalyst amount used in this oxidation reaction.

As expected from the results in homogeneous conditions, the performance of all catalysts decreased considerably in TFA (Figure 4) when compared with the ones exhibited in the greener aqueous mixture (a maximum of $14.2 \%$ yield of acetic acid is attained for 1@CNT-ox-Na, entry 7, Table 3). 
Table 4. Direct oxidation of ethane to acetic acid catalysed by compounds 1-4 heterogenised on selected carbon materials ${ }^{a}$.

\begin{tabular}{|c|c|c|c|c|c|c|c|}
\hline Entry & Catalyst & $\begin{array}{l}\text { Catalyst Amount } \\
\quad(\mu \mathrm{mol} \mathrm{Au})\end{array}$ & $\begin{array}{c}\text { Temperature } \\
\left({ }^{\circ} \mathrm{C}\right)\end{array}$ & Solvent & Yield $^{b}(\%)$ & TON $^{c}$ & TOF \\
\hline 1 & 1@CNT-ox-Na & 1.5 & 80 & TFA & 7.2 & 80 & 4 \\
\hline 2 & 1@CNT-ox-Na & 1.5 & 80 & $\mathrm{ACN} /$ water & 33.4 & 370 & 19 \\
\hline 3 & 1@CNT-ox-Na & 15 & 80 & TFA & 6.9 & 8 & 0 \\
\hline 4 & 1@CNT-ox-Na & 15 & 80 & $\mathrm{ACN} /$ water & 36.5 & 40 & 2 \\
\hline 5 & 1@CNT-ox-Na & 1.5 & 50 & TFA & 0.2 & 2 & 0 \\
\hline 6 & 1@CNT-ox-Na & 1.5 & 50 & $\mathrm{ACN} /$ water & 0 & 0 & 0 \\
\hline 7 & $1 @ \mathrm{CX}-\mathrm{ox}-\mathrm{Na}$ & 1.5 & 80 & TFA & 14.2 & 157 & 8 \\
\hline 8 & $1 @ \mathrm{CX}-\mathrm{ox}-\mathrm{Na}$ & 1.5 & 80 & $\mathrm{ACN} /$ water & 21.2 & 235 & 12 \\
\hline 9 & $1 @ \mathrm{AC}-\mathrm{ox}-\mathrm{Na}$ & 1.5 & 80 & TFA & 8.9 & 98 & 5 \\
\hline 10 & 1@AC-ox-Na & 1.5 & 80 & $\mathrm{ACN} /$ water & 16.2 & 179 & 9 \\
\hline 11 & 2@CNT-ox-Na & 1.5 & 80 & TFA & 8.3 & 92 & 5 \\
\hline 12 & 2@CNT-ox-Na & 1.5 & 80 & $\mathrm{ACN} /$ water & 32.7 & 322 & 16 \\
\hline 13 & 2@CNT-ox-Na & 15 & 80 & TFA & 10.1 & 11 & 1 \\
\hline 14 & 2@CNT-ox-Na & 15 & 80 & $\mathrm{ACN} /$ water & 31.6 & 35 & 2 \\
\hline 15 & 2@CNT-ox-Na & 1.5 & 50 & TFA & 0.6 & 7 & 0 \\
\hline 16 & 2@CNT-ox-Na & 1.5 & 50 & $\mathrm{ACN} /$ water & 1.1 & 12 & 1 \\
\hline 17 & 2@CX-ox-Na & 1.5 & 80 & TFA & 1.5 & 17 & 1 \\
\hline 18 & $2 @ \mathrm{CX}-\mathrm{ox}-\mathrm{Na}$ & 1.5 & 80 & $\mathrm{ACN} /$ water & 23.2 & 257 & 13 \\
\hline 19 & $2 @ A C-o x-N a$ & 1.5 & 80 & TFA & 0.8 & 9 & 0 \\
\hline 20 & 2@AC-ox-Na & 1.5 & 80 & $\mathrm{ACN} /$ water & 25.3 & 280 & 14 \\
\hline 21 & 3@CNT-ox-Na & 1.5 & 80 & TFA & 13.2 & 146 & 7 \\
\hline 22 & 3@CNT-ox-Na & 1.5 & 80 & $\mathrm{ACN} /$ water & 26.3 & 291 & 15 \\
\hline 23 & 3@CX-ox-Na & 1.5 & 80 & TFA & 12.7 & 362 & 18 \\
\hline 24 & $3 @ \mathrm{CX}-\mathrm{ox}-\mathrm{Na}$ & 1.5 & 80 & $\mathrm{ACN} /$ water & 21.6 & 239 & 12 \\
\hline 25 & 3@CX-ox-Na & 15 & 80 & TFA & 14.3 & 16 & 1 \\
\hline 26 & $3 @ \mathrm{CX}-\mathrm{ox}-\mathrm{Na}$ & 15 & 80 & $\mathrm{ACN} /$ water & 29.4 & 33 & 2 \\
\hline 27 & $3 @ \mathrm{CX}-\mathrm{ox}-\mathrm{Na}$ & 1.5 & 50 & TFA & 0 & 0 & 0 \\
\hline 28 & $3 @ \mathrm{CX}-\mathrm{ox}-\mathrm{Na}$ & 1.5 & 50 & $\mathrm{ACN} /$ water & 0 & 0 & 0 \\
\hline 29 & 3@AC-ox-Na & 1.5 & 80 & TFA & 11.4 & 126 & 6 \\
\hline 30 & 3@AC-ox-Na & 1.5 & 80 & $\mathrm{ACN} /$ water & 20.7 & 229 & 11 \\
\hline 31 & 4@CNT-ox-Na & 1.5 & 80 & TFA & 12.8 & 142 & 7 \\
\hline 32 & 4@CNT-ox-Na & 1.5 & 80 & $\mathrm{ACN} /$ water & 41.4 & 458 & 23 \\
\hline 33 & 4@CNT-ox-Na & 15 & 80 & TFA & 11.3 & 13 & 1 \\
\hline 34 & 4@CNT-ox-Na & 15 & 80 & $\mathrm{ACN} /$ water & 39.7 & 44 & 2 \\
\hline 35 & 4@CNT-ox-Na & 1.5 & 50 & TFA & 0.9 & 10 & 1 \\
\hline 36 & 4@CNT-ox-Na & 1.5 & 50 & $\mathrm{ACN} /$ water & 1.3 & 14 & 1 \\
\hline 37 & $4 @ \mathrm{CX}-\mathrm{ox}-\mathrm{Na}$ & 1.5 & 80 & TFA & 13.8 & 153 & 8 \\
\hline 38 & $4 @ \mathrm{CX}-\mathrm{ox}-\mathrm{Na}$ & 1.5 & 80 & $\mathrm{ACN} /$ water & 33.4 & 370 & 19 \\
\hline 39 & $4 @ \mathrm{AC}-\mathrm{ox}-\mathrm{Na}$ & 1.5 & 80 & TFA & 7.2 & 80 & 4 \\
\hline 40 & 4@AC-ox-Na & 1.5 & 80 & $\mathrm{ACN} /$ water & 13.4 & 148 & 8 \\
\hline
\end{tabular}

${ }^{a}$ Reaction conditions (unless stated otherwise): $p \mathrm{C}_{2} \mathrm{H}_{6} 3 \mathrm{~atm}, \mathrm{~K}_{2} \mathrm{~S}_{2} \mathrm{O}_{8}(4.33 \mathrm{mmol}), 20 \mathrm{~h}$. Reactions were performed in $5.5 \mathrm{~mL}$ of TFA or $6 \mathrm{~mL}$ of water/acetonitrile mixture. ${ }^{b}$ Yield (\%) $=$ mol of acetic acid $/ 100 \mathrm{~mol}$ of ethane. ${ }^{c} \mathrm{TON}=\mathrm{mol}$ of acetic acid $/ \mathrm{mol}$ of $\mathrm{Au} .{ }^{d} \mathrm{TOF}=(\mathrm{mol}$ of acetic acid $/ \mathrm{mol}$ of catalyst $(\mathbf{1 - 4})) /$ time.

The type of support also played a role on the catalytic activity of complexes 1-4 towards the formation of acetic acid, as depicted in Figure 4. CNT-ox-Na was the best support. The phenolate and carboxylate groups (formed by the -ox-Na treatment) might act as coordinating sites [59] for the complexes. The good performance of CNT might be caused by a textural effect (as CNT are nonporous, the reactants easily access the active), or an electronic effect (due to the graphitic structure of CNT), which can increase the interactions with the reactants or the intermediate radicals, as proposed by us on previous papers [52,62]. The $\mathrm{Au}(\mathrm{III})$ catalyst $4 @ \mathrm{CNT}$-ox-Na led to the highest acetic acid yield $(41.4 \%)$, among the commercial gold complexes $\mathbf{1}-\mathbf{4}$ heterogenised at functionalised carbon nanotubes (Figure 5). 


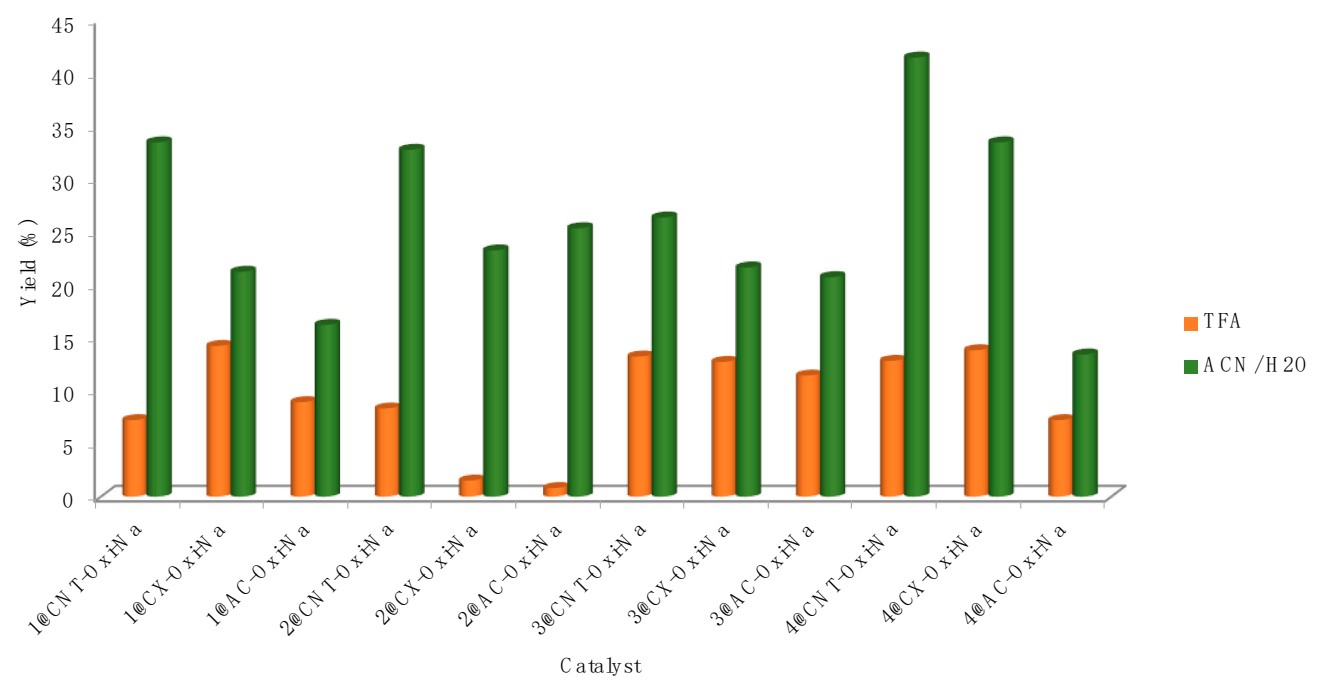

Figure 4. Acetic acid yields for the direct oxidation of ethane catalysed by the commercial gold complexes 1-4 heterogenised at carbon materials, by $\mathrm{K}_{2} \mathrm{~S}_{2} \mathrm{O}_{8}$, under optimised conditions $(1.5 \mu \mathrm{mol}$ of $\left.\mathrm{Au}, 80^{\circ} \mathrm{C}\right)$.

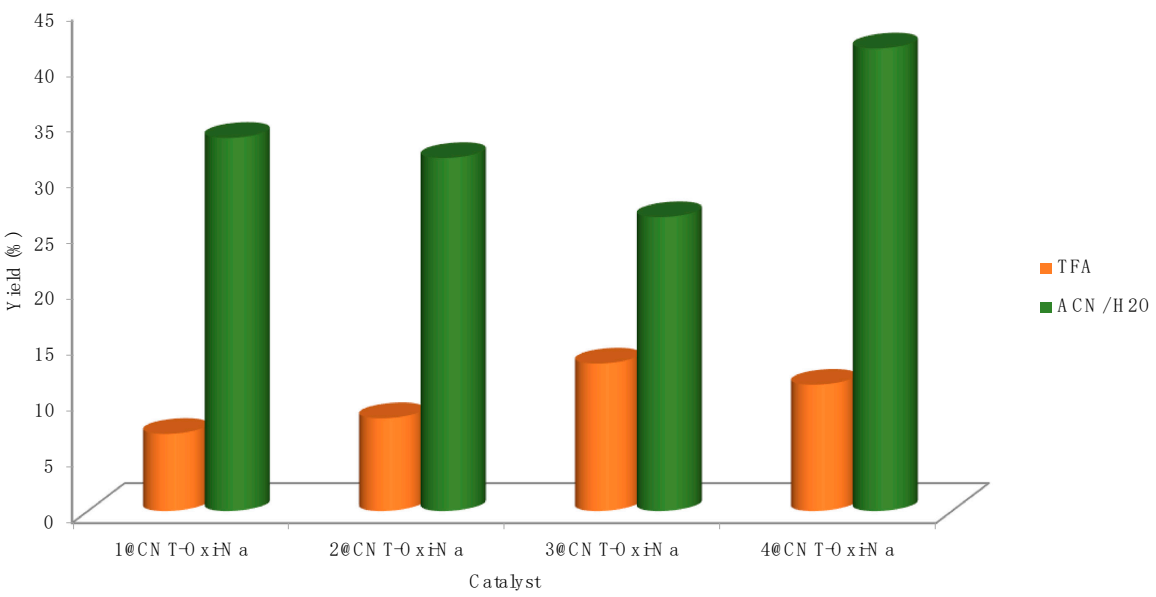

Figure 5. Acetic acid yields achieved by direct oxidation of ethane catalysed by the commercial gold complexes 1-4 heterogenised at functionalised carbon nanotubes, using $\mathrm{K}_{2} \mathrm{~S}_{2} \mathrm{O}_{8}$, under optimised conditions $\left(1.5 \mu \mathrm{mol}\right.$ of $\left.\mathrm{Au}, 80^{\circ} \mathrm{C}\right)$.

The stability of the catalysts supported on functionalised carbon nanotubes that exhibited the highest catalytic performances (acetic acid yields above 30\%, Figure 5) was investigated towards recycling experiments. Thus, each hybrid catalyst was recovered from the oxidation medium, and consecutive catalytic oxidation cycles with fresh reagents were run (see Experimental section). These catalysts were effortlessly recovered and reused up to five cycles with no significant loss of activity, while maintaining their selectivity towards the formation of acetic acid (Figure 6). Again, catalyst 4@CNT-ox-Na presented the best behaviour; its stability was less affected by the consecutive oxidative runs.

The possible gold leaching from the support as well as the formation of gold nanoparticles was accessed at the end of each catalytic cycle for catalyst 4@CNT-ox-Na. The analysis for the gold loading by inductively coupled plasma atomic emission spectroscopy (ICP-AES) of the remaining liquid phase, after the catalytic test up to the fifth run, did not show the presence of any gold. Therefore, we can assume that there was no catalyst leaching from the support. In addition, the formation of $\mathrm{Au}(0)$ nanoparticles from a possible decomposition of the gold complexes to form free gold ions was investigated by performing UV-vis spectra of the remaining liquid phase, after each catalytic cycle. No UV-plasmon 
band was observed in the usual region of 500-550 nm, indicating the absence of $\mathrm{Au}(0)$ nanoparticles formation.

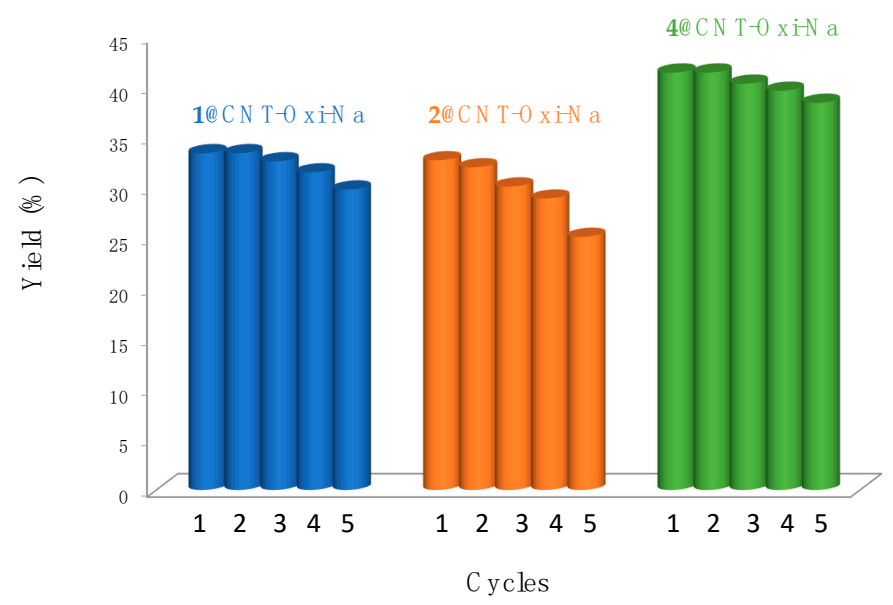

Figure 6. Recycling assays (at optimised conditions) using the commercial gold complexes 1, 2 and 4 heterogenised at functionalised carbon nanotubes.

\section{Materials and Methods}

\subsection{General Reagents}

All solvents and reagents were purchased from commercial companies and used as received.

\subsection{Gold Complexes}

Different $\mathrm{Au}(\mathrm{I})$ and $\mathrm{Au}(\mathrm{III})$ complexes were used (Figure 1). The $\mathrm{Au}(\mathrm{I}) \mathrm{com}$ plexes, chlorotriphenylphosphinegold(I) (1), chlorotrimethylphosphinegold(I) (2) and 1,3-bis(2,6-diisopropylphenyl)imidazol-2-ylidenegold(I) chloride (3) were obtained from Strem Chemicals. The dichloro(2-pyridinecarboxylato)gold(III) (4), used for the first time as catalyst by Hashmi et al. [66], was purchased from Aldrich.

\subsection{Carbon Supports}

Activated carbon Norit ${ }^{\circledR}$ RO 0.8 (AC) was purchased from Sigma-Aldrich, multiwalled carbon nanotubes NC3100 (CNT) were obtained from Nanocyl ${ }^{\mathrm{TM}}$. Carbon xerogel $(\mathrm{CX})$ prepared by the condensation of resorcinol and formaldehyde, as already described [56,67]. The supports were functionalised with $5 \mathrm{M}$ nitric acid solution and subsequently treated with $\mathrm{NaOH}$, as reported elsewhere [61-63,68-72].

\subsection{Supports Characterisation}

The carbon materials were characterised by $\mathrm{N}_{2}$ adsorption $\left(-196{ }^{\circ} \mathrm{C}\right)$ on a Quantachrome Nova 4200e device and by temperature programmed desorption (TPD) with an Altamira AMI-300 apparatus. Further details can be found elsewhere [52].

\subsection{Heterogenisation Procedure}

The complexes were supported onto each carbon materials to obtain $\sim 2 \%$ Au per mass of carbon using methanol. The Au loading was determined by inductively coupled plasma atomic emission spectroscopy (ICP-AES) at the IST Analysis Lab.

\subsection{Catalytic Tests}

The catalytic oxidation of ethane to acetic acid was performed in a stainless-steel reactor. First, $4.33 \mathrm{mmol}$ of oxidant $\left(\mathrm{K}_{2} \mathrm{~S}_{2} \mathrm{O}_{8}\right)$ and $1.50 \mu \mathrm{mol}$ of catalyst (1-4) were added to $6 \mathrm{~mL}$ of $\mathrm{H}_{2} \mathrm{O} / \mathrm{CH}_{3} \mathrm{CN}$ (or $5.5 \mathrm{~mL}$ of trifluoroacetic acid). After closing the reactor, it was flushed thrice with ethane and pressurised at $3 \mathrm{~atm}(0.78 \mathrm{mmol})$, heated at $80{ }^{\circ} \mathrm{C}$ 
(higher temperatures lead to a decrease in the solubility of ethane and decomposition of the oxidant) [73] for $20 \mathrm{~h}$. Then, the reactor was cooled to room temperature, degassed, and opened. Then, $5 \mathrm{~mL}$ of diethyl ether (to cause precipitation of the homogeneous gold catalysts and extract the organic products) and $90 \mu \mathrm{L}$ de $n$-butyric acid (internal standard) were added to $1 \mathrm{~mL}$ of mixture and stirred for $30 \mathrm{~min}$. After filtration, the liquid was analysed by gas chromatography (GC) using a FISONS Instruments GC 8000 with an FID detector and a DB-WAX capillary column (internal diameter $0.32 \mathrm{~mm}$, length $30 \mathrm{~m}$ ) software using He as a carrier, with an injection temperature of $240^{\circ} \mathrm{C}$. The values were obtained by average from several runs with similar results.

Concerning the recycling experiments, each hybrid catalyst was recovered from the oxidation medium of the first catalytic cycle by separating it from the liquid phase medium by gravity filtration. The solid was washed 5 times with water/acetonitrile mixture and then 3 times with diethyl ether. Then, it was dried in an oven at $50{ }^{\circ} \mathrm{C}$ overnight. The 2 nd catalytic cycle was initiated by placing the dried recovered catalyst and all fresh reagents into the reactor and repeating the conditions of the first catalytic cycle. The following consecutive catalytic oxidation cycles, up to the 5 th one, were run in the same way.

The occurrence of leaching during the catalytic reaction or the catalyst recovery process was investigated by UV measurements of the remaining liquid phase, performed in a lambda 35, Perkin Elmer (Waltham, MA, USA).

\section{Conclusions}

The single-pot oxidation of ethane to acetic acid was studied using $\mathrm{Au}(\mathrm{I})$ or $\mathrm{Au}(\mathrm{III})$ compounds, in their homogenous forms and supported on AC-ox-Na, CX-ox- $\mathrm{Na}$ and $\mathrm{CNT}-\mathrm{ox}-\mathrm{Na}$, as catalysts. The heterogenised catalysts showed outstanding selectivity (with acetic acid being the only product detected) and much better activity than the homogenous counterparts, with acetic acid yields up to $41.4 \%$ for $4 @$ CNT-ox-Na. The presence of TFA was detrimental for the catalytic activity, showing that aqueous (green) conditions are more adequate. The best support was CNT-ox-Na. The phenolate and carboxylate groups (formed by the -ox-Na treatment) seemed to be beneficial. Selected heterogenised catalysts were easily recovered and reused up to five cycles, with no significant loss of activity, maintaining a high selectivity for acetic acid 4@CNT-ox-Na showed not only the best catalytic performance, but also the best stability in the recycling tests.

Author Contributions: Conceptualisation, A.P.C.R. and L.M.D.R.S.M.; investigation, I.A.S.M. and S.A.C.C.; writing, L.M.D.R.S.M. and S.A.C.C.; supervision, A.P.C.R. and L.M.D.R.S.M.; funding acquisition, L.M.D.R.S.M. and S.A.C.C. All authors have read and agreed to the published version of the manuscript.

Funding: This research was funded by Fundação para a Ciência e Tecnologia (FCT), projects UIDB/00100/2020 and UIDP/00100/2020 of Centro de Química Estrutural and IMS-LA/P/0056/2020. APCR thanks Instituto Superior Técnico for the Scientific Employment contract IST-ID/119/2018. IASM is thankful to FCT for her PhD fellowship (SFRH/BD/146426/2019). It was also funded by national funds though FCT, under the Scientific Employment Stimulus-Institutional Call (CEECINST/00102/2018). We also acknowledge the Associate Laboratory for Green Chemistry-LAQV financed by national funds from FCT/MCTES (UIDB/50006/2020 and UIDP/50006/2020) and Base-UIDB/50020/2020 and Programmatic-UIDP/50020/2020 funding of the Associate Laboratory LSRE-LCM.

Institutional Review Board Statement: Not applicable.

Informed Consent Statement: Not applicable.

Data Availability Statement: Data will be made available upon request.

Conflicts of Interest: The authors declare no conflict of interest. 


\section{References}

1. Martins, L.M.D.R.S. Alkanes: Properties, Production and Applications; Nova Science Publishers, Inc.: New York, NY, USA, 2019.

2. Global Acetic Acid Market to Reach 24.51 Million Tons by 2025. Available online: https://www.expertmarketresearch.com/ pressrelease/global-acetic-acid-market (accessed on 24 May 2021).

3. Bohnet, M. Ullmann's Encyclopedia of Industrial Chemistry, 6th ed.; Wiley-VCH: Weinheim, Germany, 2002.

4. Soliman, M.; Al-Zeghayera, Y.; Al-Awadi, A.S.; Al-Mayman, S. Economics of Acetic Acid Production by Partial Oxidation of Ethane. APCBEE Procedia 2012, 3, 200-208. [CrossRef]

5. Armstrong, R.D.; Hutchings, G.J.; Taylor, S.H. An Overview of Recent Advances of the Catalytic Selective Oxidation of Ethane to Oxygenates. Catalysts 2016, 6, 71. [CrossRef]

6. Vedrine, J.C. Heterogeneous catalytic partial oxidation of lower alkanes (C-1-C-6) on mixed metal oxides. J. Energy Chem. 2016, 25, 936-946. [CrossRef]

7. Bordes-Richard, E. Application of concepts in heterogeneous oxidation of hydrocarbons: Mo, V-based oxide catalysts for oxidation of ethane and of n- and i-butanes. Catal. Today 2021, 363, 15-26. [CrossRef]

8. Thorsteinson, E.M.; Wilson, T.P.; Young, F.G.; Kasai, P.H. The oxidative dehydrogenation of ethane over catalysts containing mixed oxides of molybdenum and vanadium. J. Catal. 1978, 52, 116-132. [CrossRef]

9. McCain, J.H.; Manyik, R.M.; Naumann, A.W. Ethane oxidation to ethylene and acetic-acid over molybdenium-vanadium oxide catalysts. Abstr. Pap. Am. Chem. Soc. 1987, 194, 416-INOR.

10. Rahman, F.; Loughlin, K.F.; Al-Saleh, M.A.; Saeed, M.R.; Tukur, N.M.; Hossain, M.M.; Karim, K.; Mamedov, A. Kinetics and mechanism of partial oxidation of ethane to ethylene and acetic acid over MoV type catalysts. Appl. Catal. A Gen. 2010, 375, 17-25. [CrossRef]

11. Chen, N.F.; Oshihara, K.; Ueda, W. Selective oxidation of ethane over hydrothermally synthesized Mo-V-Al-Ti oxide catalyst. Catal. Today 2001, 64, 121-128. [CrossRef]

12. Sankaranarayanan, T.M.; Ingle, R.H.; Gaikwad, T.B.; Lokhande, S.K.; Raja, T.; Devi, R.N.; Ramaswamy, V.; Manikandan, P. Selective oxidation of ethane over Mo-V-Al-O oxide catalysts: Insight to the factors affecting the selectivity of ethylene and acetic acid and structure-activity correlation studies. Catal. Lett. 2008, 121, 39-51. [CrossRef]

13. Merzouki, M.; Taouk, B.; Tessier, L.; Bordes, E.; Courtine, P.; Grasselli, R.K.; Shymanska, M.; Trifiro, F.; Bhasin, M.M.; Kallo, D.; et al. Correlation between catalytic and structural-properties of modified molybdenum and vanadium-oxides in the oxidation of ethane in acetic-acid or ethylene. St. Surf. Sci. Catal. 1993, 75, 753-764.

14. Ruth, K.; Burch, R.; Kieffer, R. Mo-V-Nb oxide catalysts for the partial oxidation of ethane - II. Chemical and catalytic properties and structure function relationships. J. Catal. 1998, 175, 27-39. [CrossRef]

15. Roussel, M.; Bouchard, M.; Bordes-Richard, E.; Karim, K.; Al-Sayari, S. Oxidation of ethane to ethylene and acetic acid by MoVNbO catalysts. Catal. Today 2005, 99, 77-87. [CrossRef]

16. Roussel, M.; Bouchard, M.; Karim, K.; Al-Sayari, S.; Bordes-Richard, E. MoVO-based catalysts for the oxidation of ethane to ethylene and acetic acid - Influence of niobium and/or palladium on physicochemical and catalytic properties. Appl. Catal. A: Gen. 2006, 308, 62-74. [CrossRef]

17. Li, X.B.; Iglesia, E. Kinetics and mechanism of ethane oxidation to acetic acid on catalysts based on Mo-V-Nb oxides. J. Phys. Chem. C 2008, 112, 15001-15008. [CrossRef]

18. Li, X.B.; Iglesia, E. Support and promoter effects in the selective oxidation of ethane to acetic acid catalyzed by Mo-V-Nb oxides. Appl. Catal. A: Gen. 2008, 334, 339-347. [CrossRef]

19. Roussel, M.; Barama, S.; Lofberg, A.; Al-Sayari, S.; Karim, K.; Bordes-Richard, E. MoV-based catalysts in ethane oxidation to acetic acid: Influence of additives on redox chemistry. Catal. Today 2009, 141, 288-293. [CrossRef]

20. Linke, D.; Wolf, D.; Baerns, M.; Timpe, O.; Schlogl, R.; Zeyss, S.; Dingerdissen, U. Catalytic partial oxidation of ethane to acetic acid over Mo1V0.25Nb0.12Pd0.0005OxI. Catalyst performance and reaction mechanism. J. Catal. 2002, 205, 16-31. [CrossRef]

21. Bergh, S.; Guan, S.H.; Hagemeyer, A.; Lugmair, C.; Turner, H.; Volpe, A.F.; Weinberg, W.H.; Mott, G. Gas phase oxidation of ethane to acetic acid using high-throughput screening in a massively parallel microfluidic reactor system. Appl. Catal. A Gen. 2003, 254, 67-76. [CrossRef]

22. Jimenez, J.D.; Mingle, K.; Bureerug, T.; Wen, C.; Lauterbach, J. Statistically Guided Synthesis of MoV-Based Mixed-Oxide Catalysts for Ethane Partial Oxidation. Catalysts 2018, 8, 370. [CrossRef]

23. Ueda, W.; Chen, N.F.; Oshihara, K. Hydrothermal synthesis of Mo-V-M-O complex metal oxide catalysts active for partial oxidation of ethane. Chem. Commun. 1999, 517-518. [CrossRef]

24. Zhang, Y.H.; Zhong, S.H. Silica-supported MoVNbO complex oxide catalyst for low-temperature oxidation of ethane to acetic acid. Chin. J. Catal. 2005, 26, 719-723.

25. Roy, M.; GubelmannBonneau, M.; Ponceblanc, H.; Volta, J.C. Vanadium-molybdenum phosphates supported by $\mathrm{TiO}_{2}$-anatase as new catalysts for selective oxidation of ethane to acetic acid. Catal. Lett. 1996, 42, 93-97. [CrossRef]

26. Al-Zeghayer, Y.S.; Al-Awadi, A.S.; Jibril, B.Y.; Soliman, M.A.; Al-Mayman, S. Partial Oxidation of Ethane to Acetic Acid on Titania Supported MoVNbPd Catalyst. Asian J. Chem. 2013, 25, 7979-7985. [CrossRef]

27. Che-Galicia, G.; Ruiz-Martinez, R.S.; Lopez-Isunza, F.; Castillo-Araiza, C.O. Modeling of oxidative dehydrogenation of ethane to ethylene on a $\mathrm{MoVTeNbO} / \mathrm{TiO}_{2}$ catalyst in an industrial-scale packed bed catalytic reactor. Chem. Eng. J. 2015, 280, 682-694. [CrossRef] 
28. Al-Mayman, S.I.; Al-Awadi, A.S.; Al-Zeghayer, Y.A.; Soliman, M.A. Partial Oxidation of Ethane to Acetic Acid using a Metallic Pd Promoted MoVNb Catalyst Supported on Titania. J. Chem. Soc. Pakistan 2018, 40, 76-88.

29. Al-Mayman, S.I.; Soliman, M.A.; Al-Awadi, A.S.; Al-Zeghayer, Y.S. Reaction kinetics of ethane partial oxidation to acetic acid. Appl. Petrochem. Res. 2018, 8, 29-38. [CrossRef]

30. Roy, M.; Ponceblanc, H.; Volta, J.C. Vanadium-molybdenum phosphates supported by $\mathrm{TiO}_{2}$ for ethane oxidation to acetic acid: A correlation between the local environment of vanadium and the reactivity. Top. Catal. 2000, 11, 101-109. [CrossRef]

31. Sopa, A.; Waclaw-Held, A.; Grossy, M.; Pijanka, J.; Nowinska, K. Ethane to acetic acid oxidation over supported heteropoly acids. Appl. Catal. A: Gen. 2005, 285, 119-125. [CrossRef]

32. Fakeeha, A.H.; Fahmy, Y.M.; Soliman, M.A.; Alwahabi, S.M. A kinetic model for partial oxidation of ethane to acetic acid on promoted VPO catalyst. J. Chem. Technol. Biotechnol. 2000, 75, 1160-1168. [CrossRef]

33. Tessier, L.; Bordes, E.; Gubelmannbonneau, M. Active specie on vanadium-contaning catalysts for the selective oxidation of ethane to acetic-acid. Catal. Today 1995, 24, 335-340. [CrossRef]

34. Enache, D.I.; Bordes, E.; Ensuque, A.; Bozon-Verduraz, F. Vanadium oxide catalysts supported on titania and zirconia II. Selective oxidation of ethane to acetic acid and ethylene. Appl. Catal. A Gen. 2004, 278, 103-110.

35. Rahmana, A.; Indo, R.; Hagiwara, H.; Ishihara, T. Direct conversion of ethane to acetic acid over $\mathrm{H}-\mathrm{ZSM}-5$ using $\mathrm{H}_{2} \mathrm{O}_{2}$ in aqueous phase. Appl. Catal. A Gen. 2013, 456, 82-87. [CrossRef]

36. Forde, M.M.; Armstrong, R.D.; Hammond, C.; He, Q.; Jenkins, R.L.; Kondrat, S.A.; Dimitratos, N.; Lopez-Sanchez, J.A.; Taylor, S.H.; Willock, D.; et al. Partial Oxidation of Ethane to Oxygenates Using Fe- and Cu-Containing ZSM-5. J. Am. Chem. Soc. 2013, 135, 11087-11099. [CrossRef] [PubMed]

37. Armstrong, R.D.; Freakley, S.J.; Forde, M.M.; Peneau, V.; Jenkins, R.L.; Taylor, S.H.; Moulijn, J.A.; Morgan, D.J.; Hutchings, G.J. Low temperature catalytic partial oxidation of ethane to oxygenates by Fe- and Cu-ZSM-5 in a continuous flow reactor. J. Catal. 2015, 330, 84-92. [CrossRef]

38. Forde, M.M.; Armstrong, R.D.; McVicker, R.; Wells, P.P.; Dimitratos, N.; He, Q.; Lu, L.; Jenkins, R.L.; Hammond, C.; Lopez-Sanchez, J.A.; et al. Light alkane oxidation using catalysts prepared by chemical vapour impregnation: Tuning alcohol selectivity through catalyst pre-treatment. Chem. Sci. 2014, 5, 3603-3616. [CrossRef]

39. Li, Y.T.; Tang, Y.; Nguyen, L.; Tao, F.F. Catalytic Oxidation of Ethane to Carboxylic Acids in the Liquid Phase at Near Room Temperature at Ambient Pressure. ACS Sust. Chem. Eng. 2019, 7, 4707-4715. [CrossRef]

40. Liu, B.Y.; Oh, S.C.; Chen, H.Y.; Liu, D.X. The effect of oxidation of ethane to oxygenates on Pt- and Zn-containing LTA zeolites with tunable selectivity. J. Energy Chem. 2019, 30, 42-48. [CrossRef]

41. Jin, R.X.; Peng, M.; Li, A.; Deng, Y.C.; Jia, Z.M.; Huang, F.; Ling, Y.J.; Yang, F.; Fu, H.; Xie, J.L.; et al. Low Temperature Oxidation of Ethane to Oxygenates by Oxygen over Iridium-Cluster Catalysts. J. Am. Chem. Soc. 2019, 141, 18921-18925. [CrossRef]

42. Alegria, E.C.B.; Kirillova, M.V.; Martins, L.; Pombeiro, A.J.L. Pyrazole and trispyrazolylmethane rhenium complexes as catalysts for ethane and cyclohexane oxidations. Appl. Catal. A: Gen. 2007, 317, 43-52. [CrossRef]

43. Alegria, E.C.B.A.; Martins, L.M.D.R.S.; Guedes da Silva, M.F.C.; Pombeiro, A.J.L. Syntheses and Properties of Re(III) Complexes Derived from Hydrotris(1-pyrazolyl)methanes. Molecular Structure of $\left[\operatorname{ReCl}_{2}\left(\mathrm{HCpz}_{3}\right)\left(\mathrm{PPh}_{3}\right)\right]\left[\mathrm{BF}_{4}\right]$. J. Organomet. Chem. 2005, 690, 1947-1958. [CrossRef]

44. Alvarez, L.X.; Sorokin, A.B. Mild oxidation of ethane to acetic acid by $\mathrm{H}_{2} \mathrm{O}_{2}$ catalyzed by supported mu-nitrido diiron phthalocyanines. J. Organomet. Chem. 2015, 793, 139-144. [CrossRef]

45. Matias, I.A.S.; Ribeiro, A.P.C.; Martins, L.M.D.R.S. Selective oxidation of ethane to acetic acid catalyzed by a C-scorpionate iron(II) complex: Homogeneous vs. heterogeneous. Molecules 2020, 25, 5642. [CrossRef] [PubMed]

46. Shahzad, S.A.; Sajid, M.A.; Khan, Z.A.; Canseco-Gonzalez, D. Gold catalysis in organic transformations: A review. Synth. Commun. 2017, 47, 735-755. [CrossRef]

47. Scurrell, M.S. Thoughts on the use of gold-based catalysts in environmental protection catalysis. Gold Bull. 2017, 50, 77-84. [CrossRef]

48. Pflasterer, D.; Hashmi, A.S.K. Gold catalysis in total synthesis-recent achievements. Chem. Soc. Rev. 2016, 45, 1331-1367. [CrossRef] [PubMed]

49. Carabineiro, S.A.C. Supported Gold Nanoparticles as Catalysts for the Oxidation of Alcohols and Alkanes. Front. Chem. 2019, 7, 702. [CrossRef]

50. Wang, Y.L.; Gurses, S.; Felvey, N.; Kronawitter, C.X. Room temperature and atmospheric pressure aqueous partial oxidation of ethane to oxygenates over AuPd catalysts. Catal. Sci. Technol. 2020, 10, 6679-6686. [CrossRef]

51. Ribeiro, A.P.C.; Matias, I.A.S.; Zargaran, P.; Hashmi, A.S.K.; Martins, L.M.D.R.S. Unprecedented Use of NHC Gold (I) Complexes as Catalysts for the Selective Oxidation of Ethane to Acetic Acid. Materials 2021, 14, 4294. [CrossRef]

52. Carabineiro, S.A.C.; Martins, L.M.D.R.S.; Pombeiro, A.J.L.; Figueiredo, J.L. Commercial Gold(I) and Gold(III) Compounds Supported on Carbon Materials as Greener Catalysts for the Oxidation of Alkanes and Alcohols. ChemCatChem 2018, 10, 1804-1813. [CrossRef]

53. Figueiredo, J.L.; Pereira, M.F.R.; Freitas, M.M.A.; Órfão, J.J.M. Modification of the surface chemistry of activated carbons. Carbon 1999, 37, 1379-1389. [CrossRef]

54. Figueiredo, J.L.; Pereira, M.F.R.; Freitas, M.M.A.; Órfão, J.J.M. Characterization of active sites on carbon catalysts. Ind. Eng. Chem. Res. 2007, 46, 4110-4115. [CrossRef] 
55. Carabineiro, S.A.C.; Pereira, M.F.R.; Órfão, J.J.M.; Figueiredo, J.L. Surface Chemistry of Activated Carbons. In Activated Carbon: Classifications, Properties and Applications; Kwiatkowski, J.F., Ed.; Nova Science Pub Inc.: New York, NY, USA, 2011 ; pp. 125-168.

56. Carabineiro, S.A.C.; Thavorn-Amornsri, T.; Pereira, M.F.R.; Figueiredo, J.L. Adsorption of ciprofloxacin on surface-modified carbon materials. Water Res. 2011, 45, 4583-4591. [CrossRef] [PubMed]

57. Carabineiro, S.A.C.; Thavorn-Amornsri, T.; Pereira, M.F.R.; Serp, P.; Figueiredo, J.L. Comparison between activated carbon, carbon xerogel and carbon nanotubes for the adsorption of the antibiotic ciprofloxacin. Catal. Today 2012, 186, 29-34. [CrossRef]

58. Figueiredo, J.L. Functionalization of porous carbons for catalytic applications. J. Mater. Chem. A 2013, 1, 9351-9364. [CrossRef]

59. Maia, F.; Mahata, N.; Jarrais, B.; Silva, A.R.; Pereira, M.F.R.; Freire, C.; Figueiredo, J.L. Jacobsen catalyst anchored onto modified carbon xerogel as enantioselective heterogeneous catalyst for alkene epoxidation. J. Mol. Catal. A Chem. 2009, 305, 135-141. [CrossRef]

60. Figueiredo, J.L.; Pereira, M.F.R. The role of surface chemistry in catalysis with carbons. Catal. Today 2010, 150, 2-7. [CrossRef]

61. Sutradhar, M.; Martins, L.M.D.R.S.; Carabineiro, S.A.C.; Guedes da Silva, M.F.C.; Buijnsters, J.G.; Figueiredo, J.L.; Pombeiro, A.J.L. Oxidovanadium $(\mathrm{V})$ complexes anchored on carbon materials as catalysts for the oxidation of 1-phenylethanol. ChemCatChem 2016, 8, 2254-2266. [CrossRef]

62. Peixoto de Almeida, M.; Martins, L.M.D.R.S.; Carabineiro, S.A.C.; Lauterbach, T.; Rominger, F.; Hashmi, A.S.K.; Pombeiro, A.J.L.; Figueiredo, J.L. Homogeneous and Heterogenised New Gold C-Scorpionate Complexes as Catalysts for Cyclohexane Oxidation. Catal. Sci. Technol. 2013, 3, 3056-3069. [CrossRef]

63. Martins, L.M.D.R.S.; Ribeiro, A.P.C.; Carabineiro, S.A.C.; Figueiredo, J.L.; Pombeiro, A.J.L. Highly efficient and reusable CNT supported iron(ii) catalyst for microwave assisted alcohol oxidation. Dalton Trans. 2016, 45, 6816-6819. [CrossRef]

64. Kirillov, A.M.; Haukka, M.; Kirillova, M.V.; Pombeiro, A.J.L. Single-Pot Ethane Carboxylation Catalyzed by New Oxorhenium(V) Complexes with N,O Ligands. Adv. Synth. Catal. 2005, 347, 1435-1446. [CrossRef]

65. Kirillova, M.V.; Kirillov, A.M.; Reis, P.M.; Silva, J.A.L.; Fraústo da Silva, J.J.R.; Pombeiro, A.J.L. Group 5-7 transition metal oxides as efficient catalysts for oxidative functionalization of alkanes under mild conditions. J. Catal. 2007, 248, 130-136. [CrossRef]

66. Hashmi, A.S.K.; Weyrauch, J.P.; Rudolph, M.; Kurpejović, E. Gold Catalysis: The Benefits of N and N,O Ligands. Angew. Chem. Int. Ed. 2004, 43, 6545-6547. [CrossRef] [PubMed]

67. Mahata, N.; Silva, A.R.; Pereira, M.F.R.; Freire, C.; de Castro, B.; Figueiredo, J.L. Anchoring of a [Mn(salen)Cl] complex onto mesoporous carbon xerogels. J. Coll. Interf. Sci. 2007, 311, 152-158. [CrossRef] [PubMed]

68. Mahata, N.; Pereira, M.F.R.; Suárez-García, F.; Martínez-Alonso, A.; Tascón, J.M.D.; Figueiredo, J.L. Tuning of texture and surface chemistry of carbon xerogels. J. Coll. Interf. Sci. 2008, 324, 150-155. [CrossRef]

69. Martins, L.M.D.R.S.; Peixoto de Almeida, M.; Carabineiro, S.A.C.; Figueiredo, J.L.; Pombeiro, A.J.L. Heterogenisation of a C-scorpionate Fe(II) complex in carbon materials for cyclohexane oxidation. Chem CatChem 2013, 5, 3847-3856. [CrossRef]

70. Ribeiro, A.P.C.; Martins, L.M.D.R.S.; Carabineiro, S.A.C.; Figueiredo, J.L.; Pombeiro, A.J.L. Gold Nanoparticles Deposited on Surface Modified Carbon Xerogels as Reusable Catalysts for Cyclohexane C-H Activation in the Presence of CO and Water. Molecules 2017, 22, 603. [CrossRef]

71. Ribeiro, A.P.C.; Martins, L.M.D.R.S.; Carabineiro, S.A.C.; Figueiredo, J.L.; Pombeiro, A.J.L. Gold nanoparticles deposited on surface modified carbon materials as reusable catalysts for hydrocarboxylation of cyclohexane. Appl. Catal. A Gen. 2017, 547, 124-131. [CrossRef]

72. Wang, J.; Martins, L.M.D.R.S.; Ribeiro, A.P.C.; Carabineiro, S.A.C.; Figueiredo, J.L.; Pombeiro, A.J.L. Supported C-Scorpionate Vanadium(IV) Complexes as Reusable Catalysts for Xylene Oxidation. Chem. Asian J. 2017, 12, 1915-1919. [CrossRef]

73. Nakata, K.; Yamaoka, Y.; Miyata, T.; Taniguchi, Y.; Takaki, K.; Fujiwara, Y. Palladium(II) and/or copper(II)-catalyzed carboxylation of small alkanes such as methane and ethane with carbon monoxide. J. Organomet. Chem. 1994, 473, 329-334. [CrossRef] 